\title{
黄土中磁性矿物的穆斯堡尔效应及其 磁化率机理解析
}

\author{
徐 立* 刘东生 陈明扬 李 哲 \\ (中国科学院地质研究所, 北京 100029)
}

\section{关键词磁性矿物、愁斯堡尔效应、磁化率}

1984 年 Heller 和刘东生教授首次把磁化率这一物理参数引入中国黄土研究 ${ }^{\omega}$, 用来批 述古土壤一黄土地层序列, 同时发现古土壤一黄土磁化率曲线与深海氧闰位䇣变化曲线间具有 良好的可比性. 自此以后, 磁化率曲线在黄土第四纪地质研究中得以广泛地应用 ${ }^{[2,3]}$. 前人对 磁化率成因机理的研究主要集中在岩石磁学方面的工作: 磁物相测试与磁粒度测试 ${ }^{1{ }^{1}(3,43}$. 本 文主要运用穆斯㷛尔谱学方法研究黄土一古土壤的细粒级的磁性矿物, 做部分矿物学方酒的工 作, 这有助于我们理解古土镶一黄土地层序列中磁性矿物的来源、黄土磁化率变化机理.

\section{一、样品制备一一高梯度磁选法}

样品野外采自陕西洛川坡头剖面, 利用高梯度磁选法提取其中磁性矿物 ${ }^{[5,6]}$. 高梯度磁选 法的原理为: 在工作磁场中, 磁场非均匀, 内部各处汤强有差异, 形成梯度般的变化, 磁颗粓仼 其中产生净磁作用力, 当净磁力较颗粒的重力、水的粘滞力大, 磁性颗粒就被吸附, 非磁性物质 不能吸附而成尾矿. 当磁场强度很低、磁场梯度较高时, 就能分离出强磁性矿物。实验中, 为 了制造出一低强度、高梯度, 在场内一般添加钢毛, 以增加磁场梯度.

取洛川 $\mathrm{S}_{1}$ 古土壤样品 $50 \mathrm{~g}$, 加一定量的蒸馏水, 少量的 $0.005 \mathrm{~mol} / \mathrm{L}$ 六偏磷酸纳 $\left(\mathrm{NaPO}_{3}\right)_{6}$, 高能超声波工作 $30 \mathrm{~min}$, 稀释溶液至 $0.5 \mathrm{vol} \%$; 用 XCSQ 湿式磁选机, 场强 $5 \times 10^{-2} \mathrm{~T}$; 选朋 内装钢毛的有机玻璃管 (钢毛为 $90 \times 40 \mu \mathrm{m}$ ), 采用下给料, 循环提耿, 得磁性分离物.

对磁性分离物运用 Stokes 沉降原理分成: $>8 \mu \mathrm{m}, 8-2 \mu \mathrm{m},<2 \mu \mathrm{m}$ 三组粒级. 取 $<$ $2 \mu \mathrm{m}$ 的磁性分离物进行室温穆斯堡尔谱分析.

\section{二、穆斯堡尔谱分析及结果}

测量是利用 M-500 谱仪记录穆斯堡尔谱, 谱仪与 Canberra 系列 35-1024 多道分析器 联用, 使用 $50 \mathrm{mCi}^{57} \mathrm{Co}(\mathrm{Pd})$ 作为放射源, 探测器为氙 (甲烷) 正比计数器, 用铁䇴对谱仪进行 校准,并以它作为同质异能位移的参考物质.

图 1 为样品细粒磁性分离物的室温穆斯堡尔谱图, 由计算机最小二乘法拟合给出穆斯堡 尔参数, 列入表 1 中.

本文 1990 年 9 月 7 日收到.

* 现通讯地址: 中国科学院研究生院堵学部, 北京 100039 .

1) 刘秀铭,中国黄土磁学研究, 1989 .

第 13 期

科学通报

1011 


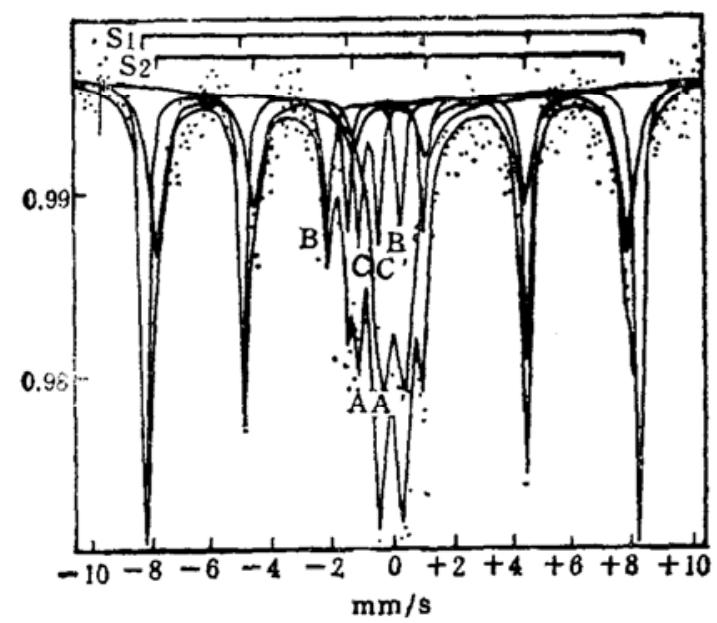

图 1 细粒磁性分离物室温穆斯堡尔谱图

表 1 细粒磁性分离物室温稿斯堡尔参数

\begin{tabular}{|c|c|c|c|c|c|c|c|}
\hline 样号 & 拟合谱 & $\begin{array}{c}\text { 同质异能移 } \\
(\mathrm{mm} / \mathrm{s})\end{array}$ & $\begin{array}{c}\text { 四极矩分裂 } \\
(\mathrm{mm} / \mathrm{s})\end{array}$ & $\begin{array}{c}\text { 内磁场 } \\
\left(1 / 4 \pi \times 10^{6}\right. \\
\mathrm{A} / \mathrm{m}) \\
\end{array}$ & $\begin{array}{c}\text { 峰面积 } \\
(\%)\end{array}$ & $\begin{array}{c}\text { 线䆓 } \\
(\mathrm{mm} / \mathrm{s})\end{array}$ & 主要矿物 \\
\hline \multirow{3}{*}{ LC } & $\mathrm{S}_{1}$ & 0.30 & 0.23 & 519.2 & 17.7 & 0.28 & 赤铁矿 \\
\hline & $\mathrm{S}_{2}$ & 0.25 & 0.11 & 494.9 & 16.2 & 0.64 & 磁赤铁 $\tilde{E}^{*}$ \\
\hline & $\mathrm{AA}^{\prime}$ & 0.13 & 0.84 & & 45.9 & 0.80 & 含 $\mathrm{Fe}^{3+}$ 研物 \\
\hline \multirow[t]{2}{*}{$S_{1-83}$} & $\mathrm{BB}^{\prime}$ & 1.15 & $2.4 \%$ & & 10.4 & 0.34 & 含 $\mathrm{Fe}^{2+}$ 矿物 \\
\hline & $\mathrm{CC}^{\prime}$ & 1.02 & 0.68 & & 9.8 & 0.30 & 食 $\mathrm{Fe}^{2+}$ 矿物 \\
\hline
\end{tabular}

解析样品穆斯堡尔谱为五套亚谱, 其中 $S_{1} 、 S_{2}$ 是较强的两套磁分裂六线谱, 峰面积比 $S_{3}$ 占 $17.7 \%, \mathrm{~S}_{2}$ 占 $16.2 \%$, 含量较高, 为高梯度磁选后磁性矿物富集的结果. 与矿物标准穆斯 堡尔谱参数对比 ${ }^{[n]}$, 它们物相分别为: $\mathrm{S}_{1}$ 为赤铁矿 $\left(\alpha \mathrm{Fe}_{2} \mathrm{O}_{3}\right), \mathrm{S}_{2}$ 为磁赤铁矿 $\left(r \mathrm{Fe}_{2} \mathrm{O}_{3}\right)$, 比较 标准参数, 被测样品参数与标准值有些差异, 这可能与其它杂质金属离子及环境干扰等因素有 关. 另外三套亚谱, $\mathrm{AA}^{\prime}$ 是一对强四极双峰, 峰面积 $45.9 \%$, 为含 $\mathrm{Fe}^{3+}$ 矿物和部分超顺磁状 态的矿物, $\mathrm{BB}^{\prime}$ 与 $\mathrm{CC}^{\prime}$ 为两套四极双峰, 为含 $\mathrm{Fe}^{2+}$ 矿物, 它们为含铁硅酸盐 (主姴为粘土矿 物)或其它含铁矿物。

在该样品中,比较磁赤铁矿与赤铁矿的线宽, $\Gamma$ 磁赤铁矿 $/ \Gamma$ 赤铁矿 $=2.3$, 磁赤铁矿有明显 的线宽宽化现象. 这种宽化现象我们分析可能是由于以下原因引起的: (1)部分金属离子 $\mathrm{Al}^{3+}$ 、 $\mathrm{Mg}^{2+}$ 等以类质闰象的方式置换结构中的 $\mathrm{Fe}^{3+} 、 \mathrm{Fe}^{2+}$ 使磁赤铁矿线宽宽化. (2)磁赤铁矿矿物 颗粒细小产生上述宽化现象.一般当磁性物质大小处于超顺磁状态时, 磁超精细作用的六线谱 将“崩埸”成为四极双线谱, 而在样品中, 磁性颗粒细小, 不足以崩塌六线谱, 只是使谱线显著加 宽.（3)少量磁铁矿迭加的可能. 磁铁矿的标准谱型为双套磁分裂六线谱 $\mathrm{AA}^{\prime}$ 与 $\mathrm{BB}^{\prime}$, 付磁场 分别为 $\mathrm{AA}^{\prime} 490 \times\left(\frac{1}{4 \pi} \times 10^{\circ} \mathrm{A} / \mathrm{m}\right), \mathrm{BB}^{\prime} 450 \times\left(\frac{1}{4 \pi} \times 10^{\circ} \mathrm{A} / \mathrm{m}\right)$,一般其强度 $\mathrm{BB}^{\prime}$ 汋 $\mathrm{AA}^{\prime}$ 的 2 倍, 样品的解析谱中未见磁铁矿的 $\mathrm{BB}^{\prime}$ 亚谱, 但少量磁铁矿的 $\mathrm{AA}^{\prime}$ 亚谱迭加于磁赤铁矿 的线谱使其线宽宽化仍有可能.

对同样品同粒级的磁性分离物我们做了粉晶 $\mathrm{X}$ 衍射物相分析, 结果中只有赤铁矿峰, 未 见磁赤铁矿的峰出现. 一方面, 我们认为样品中磁赤铁矿颗粒很细小, $\mathrm{X}$ 衍射分析无法测试; 
另一方面表明穆斯堡尔谱学是研究细粒磁性矿物较行之有效的手殷之一. 另外, 比较前人的 工作 ${ }^{[8]}$, 在一定的样品预处理基础上进行穆斯堡尔分析能得到更有效、有意义的结果.

\section{三、磁赤铁矿与黄土磁化率机理}

古土壤一黄土磁化率是现代黄土第四纪研究坐常用手段之一,目前对其变化机理可归纳为 三种主要的解析: (1) 土壤中碳酸盐含量与孔隙度减少, 磁铁矿相对富集 ${ }^{\omega}$; (2)降尘中磁性颗 粒输入的差异 ${ }^{[2,9]} ;$; (3)成土过程中新生矿物 ${ }^{[3,4]}$. 前人对产生磁化率变化的原因认识到: 磁性 矿物的差异(磁铁矿或/和磁赤铁矿) 以及磁颗粒细粒化等,但对各粒级中究竟为何种磁性矿物 及磁性矿物的矿物学性质认识不够.

本文从穆斯堡尔谱分析人手,研究分析了细粒级中磁性分离物, 我们可以得出以下结论: 细粒级中磁性矿物为赤铁矿和细粒的磁赤铁矿, 同时, 磁铁矿在该粒级中处于次要地位. 由于 矿物磁学性质的差异, 赤铁矿为反铁磁性, 磁赤铁矿为亚铁磁性, 因而磁赤铁矿对黄土磁化率 的贡献就成为重要的因子.

这部分细微柆的磁赤铁矿存在使我们认识到在成土过程中大量的磁性新生矿物的 生 成, 它们可能是成土作用的无机含成体 ${ }^{(00)}$, 或者生物有机磁性产物 ${ }^{[11}$. 这部分成土新生矿物,我们 认为磁化率的增加与成土作用有关,它们造成了古土壤一黄士的磁化率高低变化。

致谢: 本文工作中得到胡永平、应育浦、曾贻伟、胡碧茹、赵基敏、刘秀铭等同志的帮助，作者谨致谢地。

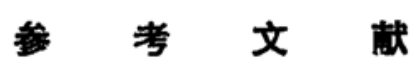

[1] Heller. F. and Liu, T.S., Geopkys. J.R. Astr. Soc., 77(1984), 125-141.

[2] Kukla, G. et al., Geology, 16(1988), 811-814.

[3] 刘秀铭等,第四纪研究, 1990,1: 42-49.

[4] Zhou, L. P. et al., Nature, 346(1990), 737-739.

[5] Petersen, N. et al., Nature, 320 (1986), 611-615.

[6] Schulze, D.G. and Dixon, J. B., Soil Sci. Soc. Am. J., 43(1979), 793-799.

[7]聂元复等,穆斯堡尔效店及其应用，原子能出版社，北京, 1984,323.

[8] 王嘉华等,黄土・第四纪地质・全球变化(第一集),科学出版社,北京, 1990,109-112.

[9] Bet, J.E. and Hawkins, D.E., Nature, 337 (1989), 151-153.

[10] Maher, B.A. and Taylor, R. M., Nature, 336 (1988), 368-370.

[11] Fassbinder, J. W. E. et sl., Neswre, 343 (1990), 161-163. 